\title{
Self-Care in Patients With Hypertension in Indonesia
}

\author{
Eldawati Eldawati1,2,", Faridah Mohd Said ${ }^{1}$, and Nur Syazana Umar' \\ ${ }^{1}$ Faculty of Nursing, Lincoln University College, Malaysia \\ ${ }^{2}$ Department of Nursing, Sekolah Tinggi llmu Kesehatan Karawang/Horizon Karawang, Indonesia \\ ORCID
}

Eldawati Eldawati: https://orcid.org/0000-0002-7337-1393

Corresponding Author: Eldawati

Eldawati; email:

elda.arif@gmail.com

Published: 7 February 2022

Publishing services provided by

Knowledge E

(c) Eldawati Eldawati et al. This article is distributed under the terms of the

Attribution License, which

permits unrestricted use and redistribution provided that the original author and source are credited.

Selection and Peer-review under the responsibility of the IVCN Conference Committee.
Abstract. Hypertension or elevated blood pressure is one of the leading causes of premature death worldwide. One strategy to better treat hypertension is to involve patients in their own self-care. This cross-sectional descriptive study was conducted in West Java, Indonesia, from June to July 2021. A convenience sample of 144 adults with hypertension was used. The inclusion criteria were: people aged 35 to 65; prescribed two or fewer antihypertensive drugs for hypertension; with a blood pressure of more than 140/90 $\mathrm{mm} \mathrm{Hg}$ at baseline; able to control their blood pressure and self-titrate medicine; and able to read and write in Bahasa Indonesia. The SC-HI is a 24-item questionnaire that assesses self-care in hypertension on three dimensions: self-care maintenance, management, and confidence. Linear regression analyses were used to investigate self-care and its associated factors. The average age of the patients was $55.67 \pm 10.65$ years, $59.7 \%$ were female, $77.8 \%$ were married, and $48.6 \%$ had finished secondary school. The mean overall self-care score among the hypertensive patients was $2.43(S D=1.26)$. The self-care domain with the lowest mean score was in confidence (mean $=2.12, \mathrm{SD}=1.96$ ) and the highest score was in maintenance (mean $=2.86, \mathrm{SD}=2.01)$. Gender, education level, and duration of hypertension contributed significantly to the variance in self-care with an R-squared of $23.4 \%$. We found that the level of self-care in the hypertensive patients in general was inadequate. Patients should be educated and counseled about the importance of adherence to self-care in the management of hypertension.

Keywords: self-care, hypertension, self-management

\section{Introduction}

Hypertension or elevated blood pressure is a serious medical condition that significantly increases the risk of heart attack, stroke, kidney failure and blindness. It is one of the leading causes of premature death worldwide [1]. The Joint National Committee on Prevention, Detection, Evaluation, and Treatment of High Blood Pressure(JNC-8) guidelines classify as normal Blood Pressure (BP) levels of less than $130 / 85 \mathrm{mmHg}$, while those of 130 to $139 \mathrm{mmHg}$ systolic and/or 85 to $89 \mathrm{mmHg}$ diastolic pre-hypertensive, 
Globally, hypertension is estimated at $26 \%$ of the world's population (972 million people), and the incidence is expect Additionally, studies have showed hypertension is one of the most common causes of cardiovascular disease $[3,4]$. Asian countries with the highest prevalence of hypertension were Japan at $60 \%$ and followed by Pakistan $(50,3 \%)$, Korea (32,9\% in male and $23.7 \%$ in women), Hong Kong (31.6\%), Malaysia (30.3\%), and India (29.8\%) while Indonesia ranked 8th at 26.5\% [5]. Research in Indonesia found that hypertension of adults $\geq 18$ years $25.8 \%$ in 2013 and increased to $34.1 \%$ In 2018 [6]. In addition, many of hypertension in Indonesia are underdiagnosed that affected to delay receiving treatment. Currently, the treatment for hypertension were focus on pharmacological approach.

One strategy to better treat hypertension, according to the World Health Organization (WHO), is to involve patients in their own self-care surveillance $[7,8]$. Self-care refers to maintaining health, monitoring for symptoms, and acting on these symptoms quickly to prevent decompensation [9]. Patients are advised to monitor their blood pressure carefully. At the same time, on medications, comply with lifestyle changes. However, in many hypertension patients, the compliance rate to self-care behaviours such as weight control, low salt intake, physical activity, and drug intake was lower [10]. In people with hypertension, poor self-care has substantial health outcomes, including elevated hospital admissions [11] and an increased risk of stroke and myocardial infarction [12,13]. Furthermore, self-care practices have been identified as one of the most important elements in reducing high blood pressure in several research $[8,14,15]$.

There are many factors that contribute to uncontrolled hypertension or under treatment and poor self-care -management of hypertension among hypertension patients. According to Mu and Mukamal (2016) some common reasons of no compliance to blood pressure treatment and self-care were the impact of side effects from medications, a patient's informed decision declining, poor control of lifestyle intervention including poor diet control and physical activities. Many studies suggested that chronic illnesses require patient's engagement to achieve maximum benefit and control of the condition. Study by Kaplan et al, (2017) identified a person's engagement as an indicator of high-quality care, lower cost, and better health. Thus, this implies that the higher the engagement the better the outcomes (Kaplan et al, 2017). Many supportive evidence showed evidence on telehealth and m-health can be used as an effective method to facilitate patient engagement. Whelton et al., (2017), clarified the effects of telehealth interventions were significantly reduced blood pressure and improved blood pressure self-monitoring. And the study concluded that telehealth with cointerventions has been shown to be an effective mediator in the management of hypertension (Whelton et al., 2017). Thus, 
this study aimed to examine self-care and its associated factors among patients with hypertension in Indonesia

\section{Methods}

\subsection{Sample and Design}

This cross-sectional descriptive study was conducted in West Java, Indonesia, from June to July 2021. A convenience sample of 144 adults with hypertension was used to assess the psychometric properties of the inventory. Individuals were recruited directly from outpatient clinical settings from hospitals in Karawang, West Java, Indonesia, using a google form, a web-based survey. The inclusion criteria were: people age 35 to 65 , diagnosed with two or less antihypertensive drugs for hypertension, had a blood pressure of more than $140 / 90 \mathrm{~mm} \mathrm{Hg}$ at baseline and were able to control their blood pressure and self-titrate medicine, and able to read and write in Bahasa Indonesia. Data was collected from March to April 2021.

\subsection{Instrument}

The sociodemographic and clinical survey contained a closed question about demographic and clinical details such as patient age, sex, educational standard, marital hypertension status, and medication numbers.

The SC-HI is a 24-item questionnaire that assesses self-care in hypertensive on three dimensions: self-care maintenance, management, and confidence. Patients who use the instrument complete it by indicating how frequently they used the scale; it includes Likert-type scales that range from "rarely or never" (1) to "always or daily" (4) for every question except two for which answers are marked with a Likert-type scale from "unrecognized" (0) to "very quickly" (4) and "nothing tried" (0) to "very sure" (4). To accomplish the self-care confidence dimension, respondents select from a range of Likert-type answers ranging from "not confident" (1) to "extremely confident" (4). The scores of each scale range from 0 to 100 , with higher scores showing better attention to themselves. A scoring of 70 or higher is deemed sufficient. A single-dimensional factor of confidence and consistency has obtained every aspect of self-care (Alpha=.83) [16] 


\subsection{Ethical consideration}

The study has been authorized in compliance with ethical standards by an affiliated university's ethical committee. Patients were given informed consent forms and surveys to sign. Everyone who participated was assured of secrecy and the opportunity to decline or withdraw completely independently and without penalty at any moment.

\subsection{Data collection procedure}

Patients completed the surveys while a regular visit to the outpatient clinics at the studied hospital. Researchers conducted two rounds of a questionnaire survey on patients in order to establish test-retest reliability. SC-HI and clinical and demographic characteristics questionnaires were included in the first list of questions.

\subsection{Data analysis}

This study was employed by the ANOVA or independent $t$ test to describe the average quotas for different demographic and clinical categories. Linear regression analyses were used to investigate self-care and its associated factors. The statistical analyses were performed using SPSS for Windows (22.0), with 0.05 being considered statistically significant.

\section{Results}

About 144 participants join in this study. Patients' average age was $55.67 \pm 10.65$ years, $59.7 \%$ were female, $77.8 \%$ were married, and $48.6 \%$ had finished secondary school. The mean duration of hypertension was $7.38 \pm 3.55$ years. The average number of antihypertensive medications taken by patients was 3.11 ( $S D=1.54)$. Gender, education level, and duration of hypertension was associated with self-care (Table 1).

Table 2 presents descriptive statistic of self-care in studied participants. The mean overall self-care score among hypertensive patients was $2.43(\mathrm{SD}=1.26)$. The lowest mean score was self-care confidence (Mean=2.12, $S D=1.96$ ) and the highest score of self-care domain was self-care maintenance (Mean=2.86, SD=2.01).

Table 3 shows simple linear regression analysis results of self-care. Gender, education level, and duration of hypertension was associated contributed significantly to the variance in self-care with $\mathrm{R}$ square was $23.4 \%$ (Table 3 ). 
TABLE 1: Sociodemographic characteristics of the sample $(N=144)$.

\begin{tabular}{|c|c|c|c|c|}
\hline \multirow[t]{2}{*}{ Variables } & & & Self-care & \\
\hline & n (\%) & Mean & SD & $p$-value \\
\hline Age, years & $55.67 \pm 10.65$ & & & 0.324 \\
\hline Female & 88 (59.7\%) & 2.54 & 1.32 & 0.022 \\
\hline Married & $112(77.8 \%)$ & 2.17 & 1.02 & 0.061 \\
\hline \multicolumn{5}{|l|}{ Education Attainment } \\
\hline Primary school & 46 (31.9\%) & 2.34 & 1.05 & 0.021 \\
\hline Secondary school & 70 (48.6\%) & 2.57 & 1.08 & \\
\hline Higher than secondary school & 28 (19.4\%) & 3.04 & 1.22 & \\
\hline Duration of Hypertension, years & $7.38 \pm 3.55$ & & & 0.002 \\
\hline Antihypertensive medication & $3.11 \pm 1.54$ & & & 0.087 \\
\hline
\end{tabular}

TABLE 2: A descriptive statistic of self-care in studied participants $(n=120)$

Scale
Overall score
Self-care Maintenance
Self-care management
Self-care confidence

Mean
2.43
2.86
2.37
2.12

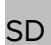

1.26

1.04

1.89

1.96

\section{Discussion}

We found that self-care level of hypertensive patients in general is inadequate. Our results also revealed insufficient self-care practices of hypertension patients towards their BP control. According to [17] the ratios for selfcare level were low in terms of medication adherence, healthful diet, physical activity, and weight management (less than 50\%) and were moderate regarding non-smoking (more than 50\%). Moreover, in many hypertension patients, the compliance rate to self-care behaviours such as weight control, low salt intake, physical activity, and drug intake was lower [10].

[18] reveals poor awareness level of the participants. This is fairly consistent with the findings of another study which has also narrated inadequate awareness among hypertensive patients [19]. However, this is incompatible with the international studies

TABLE 3: Simple linear regression analysis results of patient safety culture $(n=220)$

\begin{tabular}{l|l|l} 
Variable & Overall score B (SE) & $p$-value \\
Gender & $0.32(0.05)$ & 0.001 \\
$\begin{array}{l}\text { Education level } \\
\begin{array}{l}\text { Duration } \\
\text { Hypertension }\end{array}\end{array}$ & $0.39(0.08)$ & 0.001 \\
$\mathrm{R}^{2}$ & $0.45(0.06)$ & 0.001 \\
\hline
\end{tabular}


conducted in China [20] and USA [21] which have reported improved awareness and knowledge. These differences in results could be attributed to significant difference in literacy rates as more than half of the participants of our study had no education.

Self-care behavior is an important activity undertaken by an individual in order to improve health or prevent disease [22]. Selfcare are crucial for the prevention and management of hypertension [8]. Collective evidence revealed that adherence to selfcare lowers blood pressure, increases the efficacy of antihypertensive medications, and reduces the complications and overall mortality associated with Hypertension [23].

In people with hypertension, poor self-care has substantial health outcomes, including elevated hospital admissions [11] and an increased risk of stroke and myocardial infarction $[12,13]$. However, high quality of selfcare results in a lower incidence of comorbidities [24], and minimizing complications associated with Hypertension is a priority [25]. Many factors including socioeconomic status, belief about medications, comorbidity, availability of medications, access to healthcare, level of health literacy, number of medications, duration of therapy, age, gender, culture, educational status, and knowledge of the disease and treatment have been associated with the rate of adherence to selfcare.

There were a few limitations to our study. Most of the participants belonged to low socioeconomic status and low education. So, the results cannot be generalized to the entire population.

\section{Conclusion}

We found that self-care level of hypertensive patients in general is inadequate. Gender, education level, and duration of hypertension was associated with self-care. Healthcare providers should therefore improve their actions and also their communications with the patient to ensure a better influence on self-care behaviors. Educational programs for the youth and also the elderly should also be expanded. health care providers should pay more attention to patients at risk of having low self-care adherence. Patients should be educated and counseled about the importance of adherence to selfcare in the management of hypertension. Healthcare providers and policymakers should design educational programs that are feasible to be implemented in populations with a low level of literacy.

\section{Conflict of interest}

None. 


\section{Funding}

This research did not receive any specific grant from funding agencies in the public, commercial, or not-for-profit sectors

\section{References}

[1] Lackland D. Note from the editor president's column children's art poster contest 2019 science and art attempt to describe. 2019;(163):1-11.

[2] Unger T, Borghi C, Charchar F, et al. 2020 International Society of Hypertension global hypertension practice guidelines. Hypertension. 2020;75(6):1334-57.

[3] Dorans KS, Mills KT, Liu Y, He J. Trends in prevalence and control of hypertension according to the 2017 American College of Cardiology/American Heart Association (ACC/AHA) guideline. Journal of the American Heart Association. 2018;7(11):1-11.

[4] Tackling G, Borhade MB. Hypertensive heart disease. Treasure Island; 2021.

[5] Chia YC, Buranakitjaroen P, Chen $\mathrm{CH}$, et al. Current status of home blood pressure monitoring in Asia: Statement from the HOPE Asia Network. The Journal of Clinical Hypertension. 2017;19(11):1192-201.

[6] Riskesdas. Riset kesehatan dasar 2018. Kementrian Kesehat Republik Indones; 2018.

[7] Yang S-O, Jeong GH, Kim S-J, Lee SH. Correlates of self-care behaviors among low-income elderly women with hypertension in South Korea. Journal of Obstetric, Gynecologic \& Neonatal Nursing. 2014;43(1):97-106.

[8] Chobanian A V, Bakris GL, Black HR, et al. The seventh report of the joint national committee on prevention, detection, evaluation, and treatment of high blood pressure: The JNC 7 report. JAMA. 2003;289(19):2560-72.

[9] Silveira-Nunes G, Durso DFA, Cunha EHM, et al. Hypertension is associated with intestinal microbiota dysbiosis and inflammation in a Brazilian population. Frontiers in pharmacology. 2020;11:258.

[10] Niriayo YL, Ibrahim S, Kassa TD, et al. Practice and predictors of self-care behaviors among ambulatory patients with hypertension in Ethiopia. PLoS One. 2019;14(6):e0218947.

[11] McManus RJ, Mant J, Franssen M, et al. Efficacy of self-monitored blood pressure, with or without telemonitoring, for titration of antihypertensive medication (TASMINH4): An unmasked randomised controlled trial. Lancet. 2018;391(10124):949-59.

[12] Warren-Findlow J, Basalik DW, Dulin M, Tapp H, Kuhn L. Preliminary validation of the Hypertension Self-Care Activity Level Effects (H-SCALE) and clinical blood 
pressure among patients with hypertension. The Journal of Clinical Hypertension. 2013;15(9):637-43.

[13] Brook RD, Appel LJ, Rubenfire M, et al. Beyond medications and diet: Alternative approaches to lowering blood pressure: A scientific statement from the American Heart Association. Hypertension. 2013;61(6):1360-83.

[14] Weir MR, Maibach EW, Bakris GL, et al. Implications of a health lifestyle and medication analysis for improving hypertension control. Archives of internal medicine. 2000;160(4):481-90.

[15] Tucker KL, Sheppard JP, Stevens R, et al. Self-monitoring of blood pressure in hypertension: A systematic review and individual patient data meta-analysis. PLoS Med. 2017;14(9):e1002389.

[16] Dickson VV, Lee C, Yehle KS, Abel WM, Riegel B. Psychometric testing of the selfcare of hypertension inventory. Journal of Cardiovascular Nursing. 2017;32(5).

[17] Ma C, Kelishadi R, Hong YM, et al. Performance of eleven simplified methods for the identification of elevated blood pressure in children and adolescents. Hypertension. 2016;68(3):614-20.

[18] Bilal M, Haseeb A, Lashkerwala SS, et al. Knowledge, awareness and self-care practices of hypertension among cardiac hypertensive patients. Global Journal Health Science. 2015;8(2):9-19.

[19] Zafar SN, Gowani SA, Irani FA, Ishaq M. Awareness of the risk factors, presenting features and complications of hypertension amongst hypertensives and normotensives. J Pak Med Assoc. 2008;58(12):711-5.

[20] Li X, Zhang X, Leathers R, et al. Notch3 signaling promotes the development of pulmonary arterial hypertension. Nature medicine. 2009;15(11):1289-97.

[21] Ong KL, Cheung BMY, Man YB, Lau CP, Lam KSL. Prevalence, awareness, treatment, and control of hypertension among United States adults 1999-2004. Hypertension. 2007;49(1):69-75.

[22] Mohamed SF, Mutua MK, Wamai R, et al. Prevalence, awareness, treatment and control of hypertension and their determinants: Results from a national survey in Kenya. BMC Public Health. 2018;18(Suppl 3):1219.

[23] Weber MA. Recently published hypertension guidelines of the JNC 8 panelists, the American Society of Hypertension/International Society of Hypertension and other major organizations: Introduction to a focus issue of the Journal of Clinical Hypertension. Journal of Clinical Hypertension. 2014;16(4):241-245.

[24] Staessen JA, Wang JG, Thijs L. Cardiovascular protection and blood pressure reduction: A meta-analysis. Lancet. 2001;358(9290):1305-15. 
[25] Kearney PM, Whelton M, Reynolds K, Muntner P, Whelton PK, He J. Global burden of hypertension: Analysis of worldwide data. Lancet. 2005;365(9455):217-23. 